\title{
Targeted next-generation sequencing of dedifferentiated chondrosarcoma in the skull base reveals combined TP53 and PTEN mutations with increased proliferation index, an implication for pathogenesis
}

\author{
Lu Gao ${ }^{1, *}$, Xiafei Hong ${ }^{2, *}$, Xiaopeng Guo ${ }^{1}$, Dengfeng $\mathrm{CaO}^{3}$, Xiaohuan Gao ${ }^{4,5,10}$, Thomas \\ F. DeLaney ${ }^{6}$, Xinqi Gong ${ }^{7}$, Rongrong Chen ${ }^{8}$, Jianjiao $\mathrm{Ni}^{9}$, Yong Yao ${ }^{1}$, Renzhi Wang ${ }^{1}$, \\ Xi Chen ${ }^{4,5}$, Pangzehuan Tian ${ }^{4,5}$, Bing Xing ${ }^{1}$ \\ ${ }^{1}$ Department of Neurosurgery, Peking Union Medical College Hospital, Chinese Academy of Medical Sciences and Peking \\ Union Medical College, Beijing, China \\ ${ }^{2}$ Department of General Surgery, Peking Union Medical College Hospital, Chinese Academy of Medical Sciences and Peking \\ Union Medical College, Beijing, China \\ ${ }^{3}$ Department of Pathology and Immunology, Washington University School of Medicine, St Louis, Missouri, USA \\ ${ }^{4}$ Binhai Genomics Institute, BGI-Tianjin, Tianjin, China \\ ${ }^{5}$ Tianjin Translational Genomics Center, BGI-Tianjin, Tianjin, China \\ ${ }^{6}$ Department of Radiation Oncology, Massachusetts General Hospital, Harvard Medical School, Boston, Massachusetts, USA \\ ${ }^{7}$ Institute for Mathematical Sciences, Renmin University of China, Beijing, China \\ ${ }^{8}$ Institute of Basic Medical Sciences and School of Basic Medicine, Peking Union Medical College, Chinese Academy of Medical \\ Sciences and Peking Union Medical College, Beijing, China \\ ${ }^{9}$ Department of Medical Oncology, Peking Union Medical College Hospital, Chinese Academy of Medical Sciences and Peking \\ Union Medical College, Beijing, China \\ ${ }^{10}$ Department of Cancer Research, Jingke Biotech, Guangzhou, China \\ *These authors have contributed equally to this work \\ Correspondence to: Bing Xing, email: xingbingemail@aliyun.com \\ Keywords: dedifferentiated, chondrosarcoma, TP53, PTEN, proliferation \\ Received: November 07, $2015 \quad$ Accepted: May 08, $2016 \quad$ Published: May 26, 2016
}

\section{ABSTRACT}

Dedifferentiated chondrosarcoma (DDCS) is a rare disease with a dismal prognosis. DDCS consists of two morphologically distinct components: the cartilaginous and noncartilaginous components. Whether the two components originate from the same progenitor cells has been controversial. Recurrent DDCS commonly displays increased proliferation compared with the primary tumor. However, there is no conclusive explanation for this mechanism. In this paper, we present two DDCSs in the sellar region. Patient 1 exclusively exhibited a noncartilaginous component with a TP53 frameshift mutation in the pathological specimens from the first surgery. The tumor recurred after radiation therapy with an exceedingly increased proliferation index. Targeted next-generation sequencing (NGS) revealed the presence of both a TP53 mutation and a PTEN deletion in the cartilaginous and the noncartilaginous components of the recurrent tumor. Fluorescence in situ hybridization and immunostaining confirmed reduced DNA copy number and protein levels of the PTEN gene as a result of the PTEN deletion. Patient 2 exhibited both cartilaginous and noncartilaginous components in the surgical specimens. Targeted NGS of cells from both components showed neither TP53 nor PTEN mutations, making Patient 2 a naïve TP53 and PTEN control for comparison. In conclusion, additional PTEN loss in the background of the TP53 mutation could be the cause of increased proliferation capacity in the recurrent tumor. 


\section{INTRODUCTION}

Dedifferentiated chondrosarcoma (DDCS) is an uncommon type of chondrosarcoma with a peak incidence at 60 to 70 years of age [1]. The most frequently affected locations include the femur, pelvis, humerus and scapula. Skull involvement is extremely rare [1]. Morphologically, there are two distinct components. The cartilaginous component is characterized by well-differentiated chondrocytelike tumor cells. In contrast, the noncartilaginous dedifferentiated component is characterized by spindleshaped neoplastic cells [2]. DDCS can be further categorized into two subtypes based on the relationship between the two components. In the classical subtype $[3,4]$, the two components typically exhibit a sharp boundary with no transitional zone, whereas a clear transitional zone between the two components is observed in the non-classical type [4].

The histogenesis of DDCS remains unclear. More specifically, the origins of the cartilaginous and noncartilaginous components of DDCS remain unknown. Two theories exist with regard to the origins of the disease. The collision tumor theory $[3,5]$ states that each component originates separately from different progenitor cells. In contrast, the competing theory maintains that both components originate from the same progenitor cells and share common chondrosarcoma-associated somatic mutations $[4,6]$.

There is a dismal prognosis for this disease, for which surgical intervention remains the mainstay for treatment [1]. The value of chemotherapy remains questionable [7]. Previous studies indicate that DDCS might recur in the presence or absence of radiation therapy [2]. As previously reported [6, 8], the Ki-67 proliferation index increased when chondrosarcoma recurs; however, the mechanism remains unresolved. Previous studies $[8,9]$ have identified several frequent genetic mutations in DDCS, including $I D H 1, I D H 2$, and TP53. TP53 gene deregulation has long been suggested as a causative factor for DDCS. The TP53 protein is frequently overexpressed in DDCS $[4,10,11]$. However, TP53 alone cannot explain the increased Ki-67 index. Additional genetic or epigenetic events might account for the more rapid progression.

In this paper, we present two patients of DDCS in the skull region after radiation therapy. We used targeted next-generation sequencing (NGS) technology [12-15] to sequence a panel of genes in an attempt to discover targetable genetic changes and to decipher the pathogenesis of increased proliferation capacity in the recurrent tumor.

\section{RESULTS}

\section{Medical history, radiographic findings, treatment and pathologic findings}

\section{Patient 1}

This patient was a 28-year-old man who was admitted to a local hospital due to headache and diplopia. Magnetic resonance imaging (MRI) revealed a $2.8 \times 1.9$ $\mathrm{x} 1.8 \mathrm{~cm}$-sized mass with homogeneous enhancement in the sellar region after gadolinium injection (Figure 1A). The patient underwent a trans-sphenoidal surgery at that hospital. Hematoxylin and eosin (H\&E) staining of the resected tumor tissue (Patient-1-surgery-1 or P1-S1) revealed that the tumor cells had a spindle shape without any chondrocytic tumor cells. No tumor cells showed S-100 positivity by immunostaining (Figure 1B). No positivity was noted for neuron-specific enolase (NSE), glial fibrillary acidic protein (GFAP), epithelial membrane antigen (EMA), or actin in the tumor cells (data not shown). Therefore, no definitive diagnosis, except for a spindle cell tumor, was reached in the local hospital.

One month later, MRI detected tumor relapse, possibly derived from the remnant tumor cells. The patient then underwent a Gamma knife radiosurgery with a dose of $1260 \mathrm{cGy}$ to the tumor region (50\% isodose curve) at the local hospital in an attempt to control the recurrent tumor. Unfortunately, 4 months after the Gamma knife radiosurgery, the patient exhibited progressive decline in visual acuity, severe headaches and blepharoptosis. The patient was then transferred to our hospital, and MRI demonstrated a $3.0 \times 4.8 \times 3.5 \mathrm{~cm}$ irregular sellar cystic mass with ring-enhancement after gadolinium injection (Figure 1A). Both fluorodeoxyglucose (FDG) and tetraazacyclododecane tetraacetic acid-octreotate (DOTATATE) positron emission tomography (PET) images exhibited similar ring-shaped tracer uptake (Figure 1C). The patient then underwent a trans-sphenoidal surgery. The pathological specimen was defined as Patient-1-surgery-2 (P1-S2). H\&E staining revealed both cartilaginous (P1-S2 cart) and noncartilaginous (P1-S2 noncart) components (Figure 1A). A clear transitional zone was noted between the two components, resembling the non-classical type DDCS. The cartilaginous cells exhibited S-100 positivity by immunohistochemical staining (Figure 1B), whereas the noncartilaginous component did not (data not shown). Both components exhibited vimentin positivity, indicating a mesenchymal origin (Figure 1B). CD68 staining was positive in a portion of the cells, most likely the intermixed histiocytes (Figure 1B). The P1-S2 noncartilaginous component exhibited a similar morphology to the tumor cells in P1-S1, indicating that P1-S2 might originate from the remnant tumor cells from P1-S1. 
A

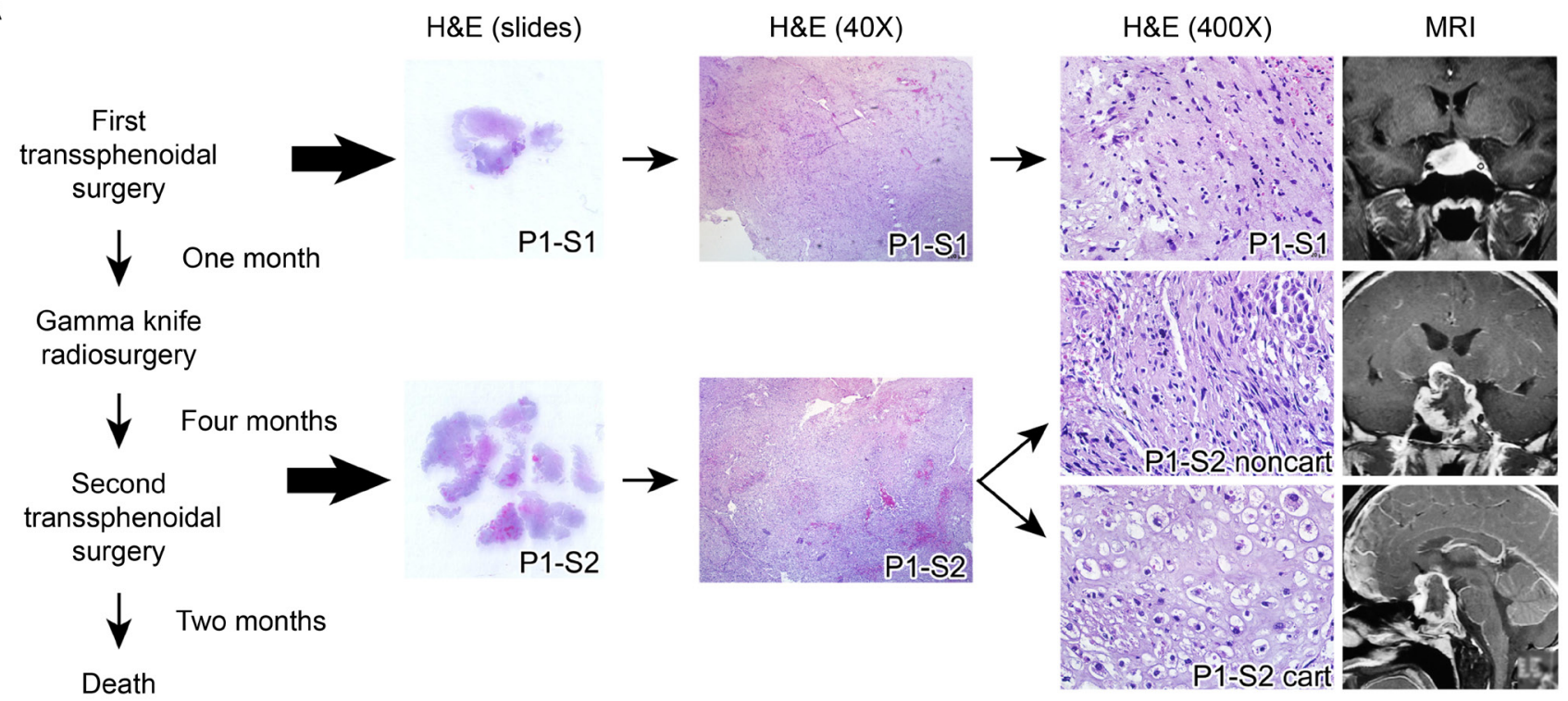

B

P1-S1

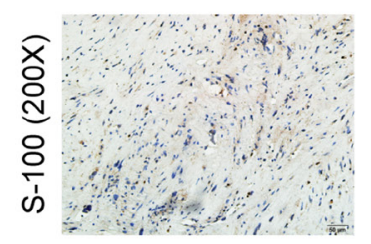

C

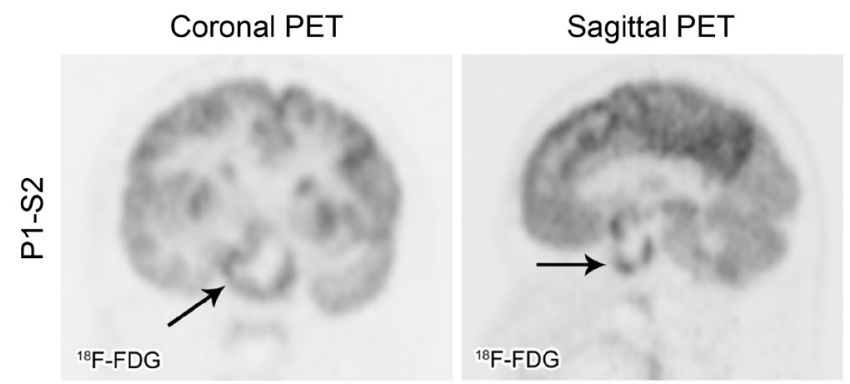

P1-S2 cart

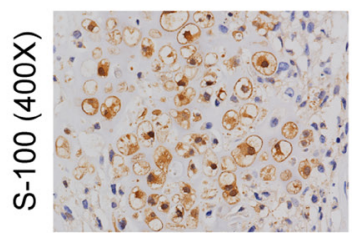

Sagittal PET
P1-S2

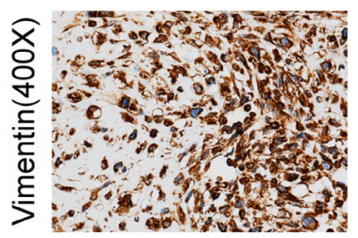

Coronal PET

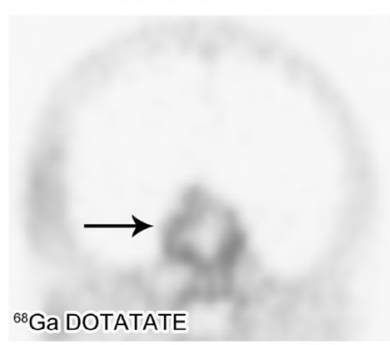

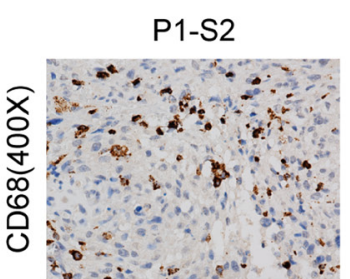

Sagittal PET

D
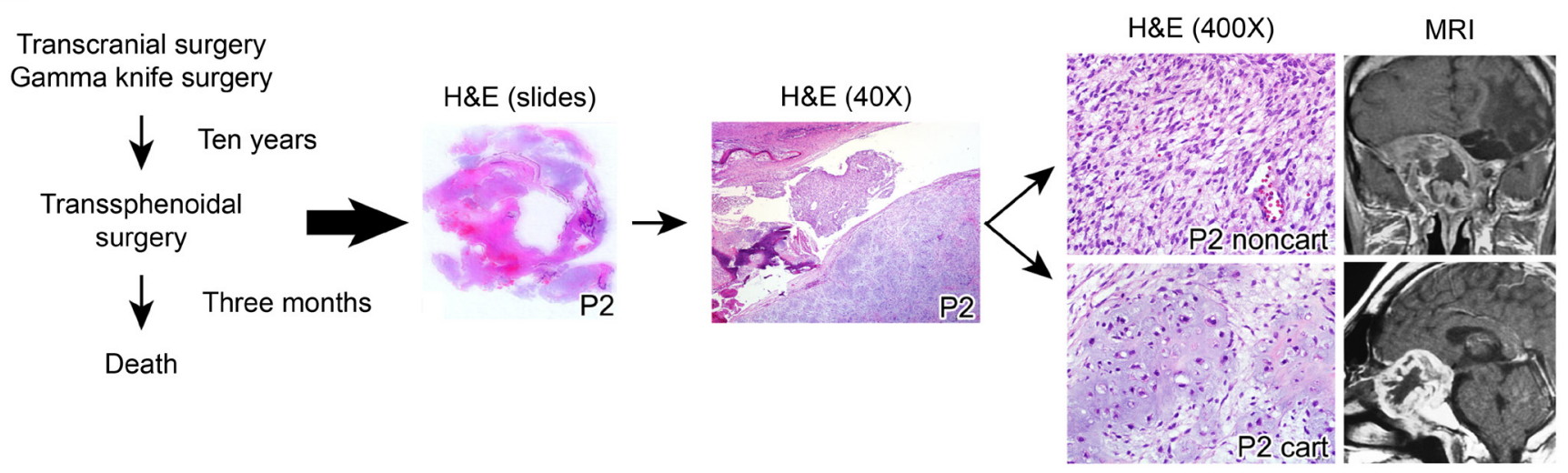

Figure 1: A. H\&E staining and enhanced MRI of Patient 1. The surgical specimen from the first surgery showed only noncartilaginous spindle-shaped tumor cells (P1-S1, upper panel). The surgical specimen from the second surgery exhibited both cartilaginous (P1-S2 cart) and noncartilaginous (P1-S2 noncart) neoplastic components (lower panel). B. Representative immunostaining images for S-100 in P1S1 as well as S-100, vimentin and CD68 in P1-S2. C. The FDG PET image demonstrated irregular ring-shaped tracer uptake in the sellar region (arrow, average SUV 2.58, SUVmax 5.16). Similarly, the DOTATATE PET image highlighted the same ring-shaped somatostatin receptor expression in the tumors (arrow, average SUV 0.67, SUVmax 1.04). D. H\&E staining and MRI of Patient 2. The surgical specimen exhibited both cartilaginous ( $\mathrm{P} 2$ cart) and noncartilaginous ( $\mathrm{P} 2$ noncart) components. 
After surgery, although his vision improved, the patient died two months later due to disease progression.

\section{Patient 2}

This patient was a 37-year-old male patient admitted to a local hospital because of headache, coarsened facial features and enlarged hands and feet. He had a history of removal of a growth hormone-secreting pituitary adenoma by a transcranial approach followed by Gamma knife radiosurgery (exact dose of radiosurgery not documented) ten years previous. At the time of admission, the patient complained of severe cephalalgia and vision loss in the right eye. This patient was then admitted to our hospital. MRI revealed a 5.6 x 5.8 x $5.0 \mathrm{~cm}$ irregular cystic mass with ring-enhancement, extending to the sphenoid sinus, cavernous sinus, clivus, and suprasellar region (Figure 1D). The patient underwent a transsphenoidal surgery but died three months later. The postoperative pathologic diagnosis was DDCS consisting of both cartilaginous (P2 cart) and noncartilaginous (P2 noncart) components. A sharp boundary was noted with no transitional zone between the cartilaginous and noncartilaginous components, resembling the classical type (Figure 1D). The noncartilaginous spindled tumor cells were negative for MyoD1, myogenin, and desmin by immunohistochemical staining (data not shown), thus excluding the possibility that the noncartilaginous component was a variant of rhabdomyosarcoma [5].

\section{Sequencing and mutation detections}

To address the question of whether the P1-S2 tumor arose from remnant tumor cells from $\mathrm{P} 1-\mathrm{S} 1$ or arose de novo, targeted NGS sequencing was conducted for the P1-S1 tissue, P1-S2 tissue and peripheral blood cell DNA. It should be noted that the P1-S2 tissue that was sequenced consisted of both cartilaginous and noncartilaginous components without further micro-dissection, as the cartilaginous component was interspersed among the noncartilaginous component and exhibited clear transitional zones in P1-S2.

Targeted NGS sequencing revealed shared frameshift mutations in TP53 c.[835delG] and three other pathogenic missense mutations, JAK1 c. $[383 \mathrm{G}>\mathrm{A}]$, MAPK8IP1 c. [1484C $>$ A] and NTRK1 c.[1925C $>$ T], in both P1-S1 and P1-S2, indicating that the tumor sample from the second surgery (recurrent tumor) was derived from the residual tissue from the first tumor. Notably, the mutation frequencies in JAK1, NTRK1, and TP53 increased in P1S2 compared with P1-S1 (Table 1; Figure 2A, left panel; Figure 2B, left panel). No detectable level of $I D H 1 / 2$ gene mutations was found in either P1-S1 or P1-S2, which is consistent with previous research demonstrating that not all chondrosarcomas harbor such mutations $[9,16]$.

Furthermore, both components in P1-S2 (60-80\%) exhibited a considerably increased Ki-67 index compared with the non-cartilaginous component (less than 3\%) in P1-S1 (Figure 2C), indicating that the tumor cells exhibited a higher degree of proliferation. P1-S2 also harbored other pathogenic mutations, such as missense mutations in NCOR1, CREBBP, RPS14 and TERT genes, and a loss of copy number in PTEN exons 1-9, indicating that additional genetic alterations were acquired during disease progression (Figure 2D).

We next asked whether both components from Patient 2 harbored mutations in either TP53 or PTEN genes. The targeted NGS revealed no pathogenic TP53 or PTEN gene mutations in either $\mathrm{P} 2$ cart or $\mathrm{P} 2$ noncart. NOTCH4 c. $[3562 \mathrm{G}>\mathrm{A}]$ was predicted to be pathogenic and present in both $\mathrm{P} 2$ cart and P2 noncart (Table 2; Figure 2A, right panel; Figure 2B, right panel). Because no peripheral blood DNA was available from this patient as a reference control, we could not determine whether the shared mutations were germline or somatic. For validation purposes, sequencing data from Patient 1 samples (P1-S1 and P1-S2) were also analyzed by MuTect v1.1.4 and Indel by Varscan v2.3.6. The mutations that were called were almost identical with those from the standard BGI in-house NGS analysis (Supplementary Table 2).

\section{Combined TP53 and PTEN loss likely resulted in an increased proliferation index after radiotherapy}

With regard to the pathogenicity, TP53 c.[835delG] was reported in five carcinoma samples in the Catalogue of Somatic Mutations in Cancer database. The International Agency for Research on Cancer (IARC) database for TP53 was investigated, and the codons close to this mutation were frequently mutated in various types of cancer [17].

The PTEN exon 1-9 region in Patient 1 revealed normal reads for $\mathrm{P} 1-\mathrm{S} 1$ but reduced reads for $\mathrm{P} 1-\mathrm{S} 2$ (Figure 2D), indicating a PTEN loss in P1-S2. To confirm this observation, fluorescence in situ hybridization (FISH) was performed, which showed both heterozygous and homozygous deletions in P1-S2, with $67 \%$ of cells exhibiting PTEN gene probe loss (11\% homozygous deletions and $56 \%$ heterozygous deletions) in randomly selected fields (Figure 2E).

To test whether the TP53 and PTEN alterations were related to cell proliferation, we searched for a differently tested sample on 'cBioPortal' (http://www.cbioportal.org/), which is an open-source, web-based analyzer [18, 19]. One dataset [20] consisting of over two hundred adult soft tissue sarcomas was analyzed, and the gene encoding the Ki-67 protein (MKI67) was elevated in 54\% of the cases, all of which displayed a deregulation of either PTEN or TP53 expression (Figure 2F).

Next, we examined the protein levels of PTEN and TP53 by immunostaining. Reduced PTEN protein levels were detected in immunostaining of P1-S2 (Figure 3A) [21]. Both P1-S1 and P1-S2 harbored the same frameshift mutation in TP53, which resulted in premature peptide 
Table 1: Sequencing data analyzed by the Standard BGI in-house NGS analysis for Patient 1

\begin{tabular}{|c|c|c|c|c|c|c|c|}
\hline Gene name & cHGVS & pHGVS_ad & $\begin{array}{c}\text { Mutation } \\
\text { type }\end{array}$ & $\begin{array}{l}\text { Mutation } \\
\text { frequencies } \\
\text { in P1-S1 }\end{array}$ & $\begin{array}{l}\text { Mutation } \\
\text { frequencies } \\
\text { in P1-S2 }\end{array}$ & Condel & Pathogenicity \\
\hline PRX & c. $[1687 \mathrm{G}>\mathrm{A}]$ & p.[A563T] & Missense & 4.27 & $\begin{array}{c}\text { Not } \\
\text { detectable }\end{array}$ & 0.313 & VUS \\
\hline SLC4A1 & c. $[931 \mathrm{C}>\mathrm{A}]$ & p.[L311I] & Missense & 5.32 & $\begin{array}{c}\text { Not } \\
\text { detectable }\end{array}$ & 0.477 & VUS \\
\hline FAT3 & c. $[8657 \mathrm{~A}>\mathrm{G}]$ & p. [D2886G] & Missense & 10 & $\begin{array}{c}\text { Not } \\
\text { detectable }\end{array}$ & 0.319 & VUS \\
\hline SPEN & c. $[811 \mathrm{G}>\mathrm{A}]$ & p.[G271S] & Missense & 11.9 & $\begin{array}{c}\text { Not } \\
\text { detectable }\end{array}$ & 0.423 & VUS \\
\hline SIK1 & c. $[1355 \mathrm{C}>\mathrm{T}]$ & p. $[\mathrm{P} 452 \mathrm{~L}]$ & Missense & 16.67 & $\begin{array}{c}\text { Not } \\
\text { detectable }\end{array}$ & 0.523 & Pathogenic \\
\hline NTRK1 & c. $[1925 \mathrm{C}>\mathrm{T}]$ & p.[A642V] & Missense & 12.5 & 17.72 & 0.540 & Pathogenic \\
\hline JAK1 & c. $[383 \mathrm{G}>\mathrm{A}]$ & p. $[\mathrm{R} 128 \mathrm{H}]$ & Missense & 23.53 & 41.48 & $\mathrm{~N} / \mathrm{A}$ & Pathogenic ${ }^{*}$ \\
\hline MAPK8IP1 & c. $[1484 \mathrm{C}>\mathrm{A}]$ & p.[A495D] & Missense & 35.71 & 28.02 & 0.750 & Pathogenic \\
\hline TP53 & c. $[835 \mathrm{delG}]$ & p.[G279fs*?] & Frameshift & 53.12 & 64.39 & N/A & Pathogenic \\
\hline NCOR1 & c. $[6591 \mathrm{G}>\mathrm{C}]$ & p. [K2197N] & Missense & $\begin{array}{c}\text { Not } \\
\text { detectable }\end{array}$ & 3.04 & 0.523 & Pathogenic \\
\hline RAD50 & c. $[323 \mathrm{~A}>\mathrm{G}]$ & p.[K108R] & Missense & $\begin{array}{c}\text { Not } \\
\text { detectable }\end{array}$ & 4.06 & 0.396 & VUS \\
\hline CREBBP & c. $[1974 \mathrm{C}>\mathrm{G}]$ & p.[I658M] & Missense & $\begin{array}{c}\text { Not } \\
\text { detectable }\end{array}$ & 8.87 & 0.592 & Pathogenic \\
\hline TSHZ3 & c. $[1804 \mathrm{~A}>\mathrm{T}]$ & p. [M602L] & Missense & $\begin{array}{c}\text { Not } \\
\text { detectable }\end{array}$ & 10.36 & 0.395 & VUS \\
\hline ARHGAP35 & c. $[3779 \mathrm{C}>\mathrm{T}]$ & p. $[\mathrm{P} 1260 \mathrm{~L}]$ & Missense & $\begin{array}{c}\text { Not } \\
\text { detectable }\end{array}$ & 14.03 & 0.442 & VUS \\
\hline RAD52 & c. $[593 \mathrm{C}>\mathrm{T}]$ & p.[P198L] & Missense & $\begin{array}{c}\text { Not } \\
\text { detectable }\end{array}$ & 18.02 & 0.467 & VUS \\
\hline NOTCH1 & c. $[658 \mathrm{G}>\mathrm{A}]$ & p.[V220M] & Missense & $\begin{array}{c}\text { Not } \\
\text { detectable }\end{array}$ & 29.21 & 0.514 & VUS \\
\hline RPS14 & c. $[341 \mathrm{C}>\mathrm{T}]$ & p. $[\mathrm{S} 114 \mathrm{~L}]$ & Missense & $\begin{array}{c}\text { Not } \\
\text { detectable }\end{array}$ & 34.89 & 0.820 & Pathogenic \\
\hline TERT & c. $[901 \mathrm{C}>\mathrm{T}]$ & p.[R301C] & Missense & $\begin{array}{c}\text { Not } \\
\text { detectable }\end{array}$ & 41.02 & 0.536 & Pathogenic \\
\hline
\end{tabular}

Abbreviations: HGVS: Human Genome Variation Society; P1-S1: Patient-1-surgery-1; P1-S2: Patient-1-surgery-2; VUS: variants of unknown significance; N/A: Not available.

* SIFT=0.00, Polyphen-2=1.000 for JAK1: c. [383G $>$ A]

termination and minimal immunostaining for the TP53 protein (Figure 3A). For Patient 2, neither the cartilaginous nor the noncartilaginous components exhibited TP53 or PTEN mutations by sequencing. PTEN showed mediumstrong immunostaining intensity in P2 cart and P2 noncart. TP53 revealed no immunostaining in either component in Patient 2 (Figure 3A). For quality control purposes, an adenocarcinoma sample was used as a positive control for TP53, and lymphocytes were used as a positive control for PTEN (Figure 3A).

\section{The other mutations in Patient 1 were not major contributors to disease progression}

Because the $J A K 1$ and NTRK1 mutation percentages were higher in P1-S2 compared with P1-S1, we were interested in whether these two mutations were accountable for the increased Ki-67 index. Recent literature has highlighted the targeting of receptor tyrosine kinases (RTKs) in human chondrosarcoma. One study [22] on humanderived chondrosarcoma cell lines revealed that targeted 
A Tp53c.[835delG] $\bullet$ JAK1c. [383G>A] $\bullet$ MAPK8IP1c.[1484C>A B - NTRK1C.[1925C>T] MSH3C.178_179insCCGCAGCGC

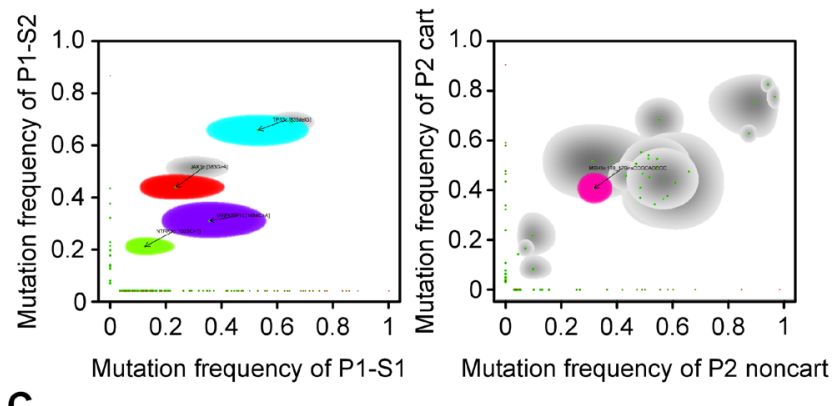

C

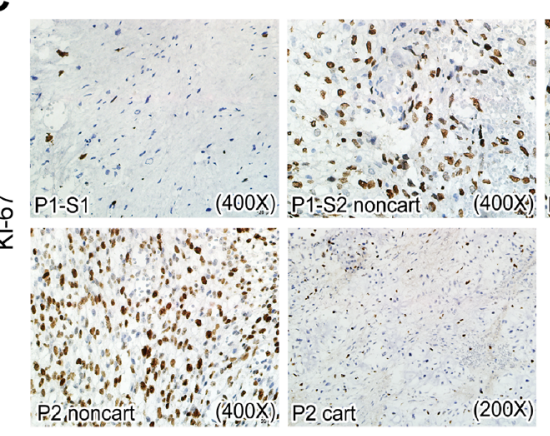

D
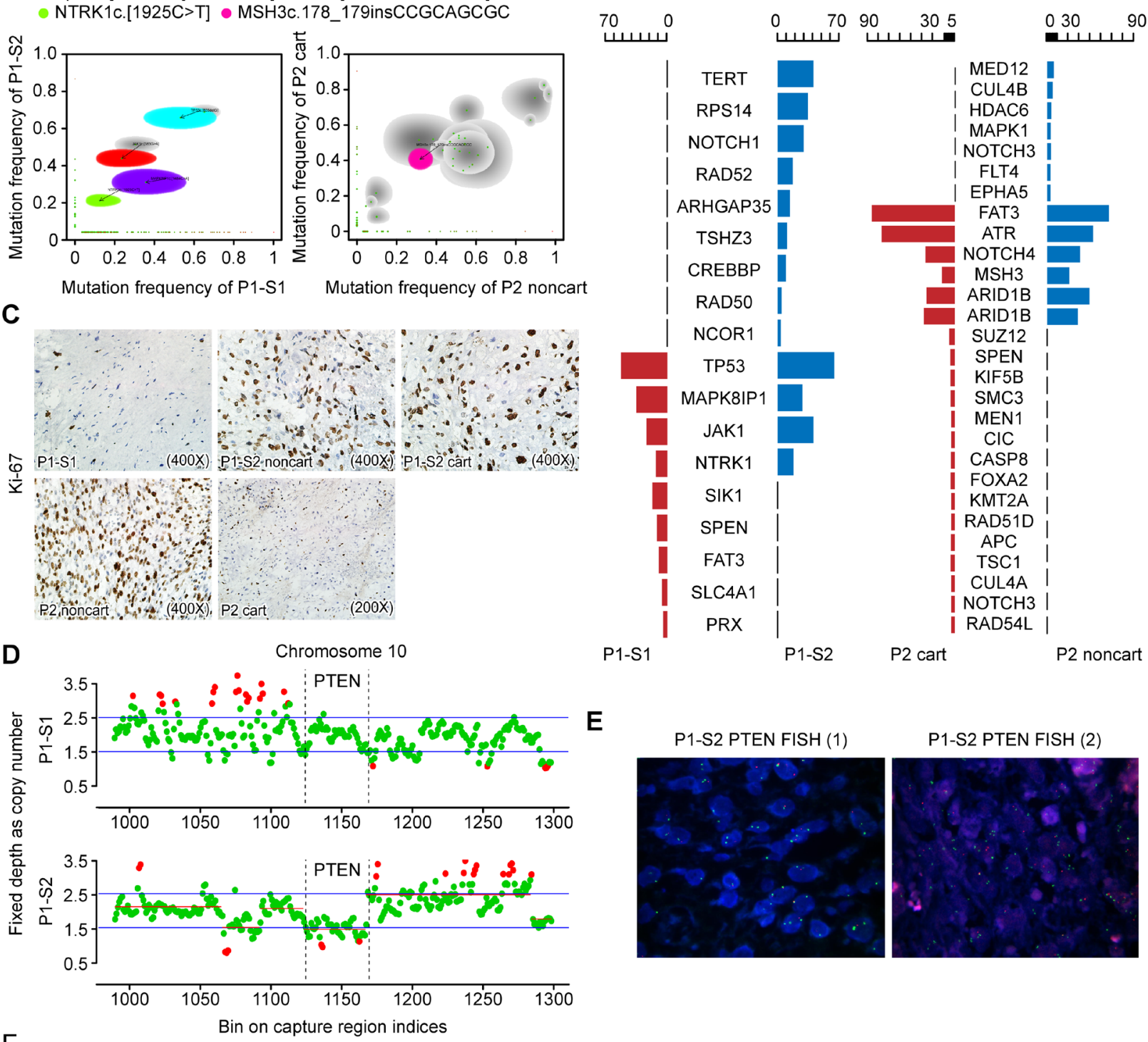

\section{E} P1-S2 PTEN FISH (1) P1-S2 PTEN FISH (2)
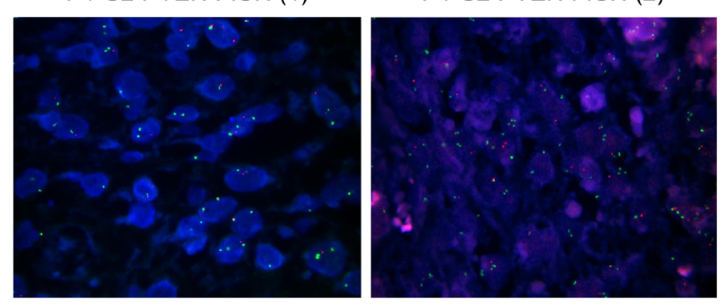

$\mathrm{F}$

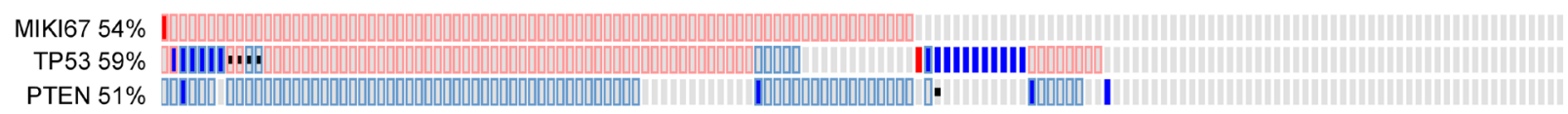

| Amplification | Deep deletion 『mRNA downregulation \mRNA upregulationn Missense mutation : Truncation mutation

Figure 2: Targeted NGS showed a combined TP53 and PTEN loss. A. A comparison of the mutation allele frequency in the P1$\mathrm{S} 1$ (x-axis) versus those in P1-S2 (y-axis) is shown (left panel). A comparison of the mutation allele frequency in the P2 noncart (x-axis) versus those in P2 cart (y-axis) is presented (right panel). Shaded areas represent Bayesian posterior probability distributions over mutation allele frequency in both samples from the same patients. Gray shading indicates mutation allele frequency distributions having considerable uncertainty, with lighter shading indicating greater uncertainty. Mutations of interest are also labeled. B. Oseq targeted sequencing revealed both shared and distinct mutations. C. Immunostaining of Ki-67 indexes in surgical specimens from P1-S1, P1-S2 noncart, P1-S2 cart, P2 noncart and P2 cart. D. Schematic view of copy number estimation from the targeted NGS depth data. The copy number of chr10 in the P1$\mathrm{S} 1$ sample revealed no copy number changes in the PTEN gene region (locus: 1123 1166) (upper), whereas the copy number of chr10 in the P1-S2 sample showed alterations in the PTEN gene exon 1-9 region (lower). E. FISH revealed heterozygous and homozygous deletions in the PTEN gene in P1-S2, with organ probes detecting PTEN and green probes detecting the alpha satellite of 10p11.1-q11.1. F. Schematic views of the expression levels of MKI67, TP53 and PTEN in a sarcoma dataset. 
Table 2: Sequencing data analyzed by the Standard BGI in-house NGS analysis for Patient 2

\begin{tabular}{|c|c|c|c|c|c|c|c|}
\hline $\begin{array}{l}\text { Gene } \\
\text { name }\end{array}$ & cHGVS & pHGVS_ad & $\begin{array}{l}\text { Mutation } \\
\text { type }\end{array}$ & $\begin{array}{l}\text { Mutation } \\
\text { frequencies } \\
\text { in } P 2 \text { cart }\end{array}$ & $\begin{array}{c}\text { Mutation } \\
\text { frequencies } \\
\text { in P2 } \\
\text { noncart }\end{array}$ & Condel & Pathogenicity \\
\hline RAD54L & c. $[460 \mathrm{C}>\mathrm{T}]$ & p.[R154W] & Missense & 3.03 & $\begin{array}{c}\text { Not } \\
\text { detectable }\end{array}$ & 0.749 & Pathogenic \\
\hline NOTCH3 & c. $[4448 \mathrm{G}>\mathrm{A}]$ & p. $[\mathrm{R} 1483 \mathrm{H}]$ & Missense & 3.06 & $\begin{array}{c}\text { Not } \\
\text { detectable }\end{array}$ & 0.351 & VUS \\
\hline CUL4A & c. $[1723 \mathrm{C}>\mathrm{T}]$ & p. $[\mathrm{H} 575 \mathrm{Y}]$ & Missense & 3.16 & $\begin{array}{c}\text { Not } \\
\text { detectable }\end{array}$ & 0.657 & Pathogenic \\
\hline TSC1 & c. $[1039 \mathrm{~T}>\mathrm{C}]$ & p.[W347R] & Missense & 3.24 & $\begin{array}{c}\text { Not } \\
\text { detectable }\end{array}$ & 0.591 & Pathogenic \\
\hline APC & c. $[1678 \mathrm{~A}>\mathrm{G}]$ & p. [K560E] & Missense & 3.27 & $\begin{array}{c}\text { Not } \\
\text { detectable }\end{array}$ & 0.593 & Pathogenic \\
\hline RAD51D & c. $[61 \mathrm{~A}>\mathrm{G}]$ & $\mathrm{p} .[\mathrm{R} 21 \mathrm{G}]$ & Missense & 3.29 & $\begin{array}{c}\text { Not } \\
\text { detectable }\end{array}$ & 0.450 & VUS \\
\hline KMT2A & c. $[6415 \mathrm{~T}>\mathrm{C}]$ & p.[Y2139H] & Missense & 3.38 & $\begin{array}{c}\text { Not } \\
\text { detectable }\end{array}$ & 0.543 & Pathogenic \\
\hline FOXA2 & c. $[69+1 \mathrm{G}>\mathrm{A}]$ & $\mathrm{N} / \mathrm{A}$ & Splice-5 & 3.42 & $\begin{array}{c}\text { Not } \\
\text { detectable }\end{array}$ & $\mathrm{N} / \mathrm{A}$ & VUS \\
\hline CASP8 & c. $[319 \mathrm{C}>\mathrm{T}]$ & p.[R107C] & Missense & 3.45 & $\begin{array}{c}\text { Not } \\
\text { detectable }\end{array}$ & 0.452 & VUS \\
\hline $\mathrm{CIC}$ & c. $[4634 \mathrm{C}>\mathrm{T}]$ & p. $[\mathrm{A} 1545 \mathrm{~V}]$ & Missense & 3.52 & $\begin{array}{c}\text { Not } \\
\text { detectable }\end{array}$ & 0.459 & VUS \\
\hline MEN1 & c. $[598 \mathrm{G}>\mathrm{A}]$ & p. $[\mathrm{G} 200 \mathrm{~S}]$ & Missense & 3.62 & $\begin{array}{c}\text { Not } \\
\text { detectable }\end{array}$ & 0.646 & Pathogenic \\
\hline SMC3 & c. $[1129 \mathrm{G}>\mathrm{A}]$ & p.[A377T] & Missense & 3.75 & $\begin{array}{c}\text { Not } \\
\text { detectable }\end{array}$ & 0.617 & Pathogenic \\
\hline KIF5B & c. $[2822 \mathrm{G}>\mathrm{A}]$ & p.[R941H] & Missense & 4.07 & $\begin{array}{c}\text { Not } \\
\text { detectable }\end{array}$ & 0.649 & Pathogenic \\
\hline SPEN & c. $[5996 \mathrm{~A}>\mathrm{G}]$ & p.[K1999R] & Missense & 4.32 & $\begin{array}{c}\text { Not } \\
\text { detectable }\end{array}$ & 0.370 & VUS \\
\hline SUZ12 & c. $[1078 \mathrm{C}>\mathrm{T}]$ & p. $[\mathrm{R} 360 \mathrm{C}]$ & Missense & 5.38 & $\begin{array}{c}\text { Not } \\
\text { detectable }\end{array}$ & 0.448 & VUS \\
\hline ARID1B & c. $[2764 \mathrm{~A}>\mathrm{T}]$ & p. $[\mathrm{M} 922 \mathrm{~L}]$ & Missense & 47.88 & 48.47 & 0.401 & VUS \\
\hline ARID1B & c. $[1025 \mathrm{C}>\mathrm{T}]$ & p. [A342V] & Missense & 45.76 & 59.26 & 0.327 & VUS \\
\hline MSH3 & $\begin{array}{c}\text { c. }\left[178 \_179\right. \\
\text { insCCGCAGCGC] }\end{array}$ & p. $\left[63 \_64\right.$ insAAP $]$ & Cds-indel & 31.82 & 40.58 & $\mathrm{~N} / \mathrm{A}$ & VUS \\
\hline NOTCH4 & c. $[3562 \mathrm{G}>\mathrm{A}]$ & p.[D1188N] & Missense & 46.77 & 50.37 & 0.574 & Pathogenic \\
\hline ATR & c. $[982 \mathrm{~A}>\mathrm{G}]$ & p.[M328V] & Missense & 87.27 & 62.56 & 0.463 & VUS \\
\hline FAT3 & c. $[10244 \mathrm{~T}>\mathrm{A}]$ & p. [L3415H] & Missense & 96.48 & 77.2 & 0.321 & VUS \\
\hline EPHA5 & c. $[16 \mathrm{C}>\mathrm{A}]$ & p. [P6T] & Missense & $\begin{array}{c}\text { Not } \\
\text { detectable }\end{array}$ & 3.17 & 0.476 & VUS \\
\hline
\end{tabular}

(Continued) 


\begin{tabular}{|c|c|c|c|c|c|c|c|}
\hline $\begin{array}{l}\text { Gene } \\
\text { name }\end{array}$ & cHGVS & pHGVS_ad & $\begin{array}{c}\text { Mutation } \\
\text { type }\end{array}$ & $\begin{array}{l}\text { Mutation } \\
\text { frequencies } \\
\text { in P2 cart }\end{array}$ & $\begin{array}{c}\text { Mutation } \\
\text { frequencies } \\
\text { in P2 } \\
\text { noncart }\end{array}$ & Condel & Pathogenicity \\
\hline FLT4 & c. $[3106 \mathrm{~A}>\mathrm{G}]$ & p.[R1036G] & Missense & $\begin{array}{c}\text { Not } \\
\text { detectable }\end{array}$ & 3.41 & 0.542 & Pathogenic \\
\hline NOTCH3 & c. $[458 \mathrm{G}>\mathrm{A}]$ & p. $[\mathrm{R} 153 \mathrm{H}]$ & Missense & $\begin{array}{c}\text { Not } \\
\text { detectable }\end{array}$ & 3.52 & 0.530 & Pathogenic \\
\hline MAPK1 & c. $[76 \mathrm{~A}>\mathrm{G}]$ & p.[T26A] & Missense & $\begin{array}{c}\text { Not } \\
\text { detectable }\end{array}$ & 3.57 & 0.492 & VUS \\
\hline HDAC6 & c. $[2764 \mathrm{C}>\mathrm{T}]$ & p.[Q922*] & Nonsense & $\begin{array}{c}\text { Not } \\
\text { detectable }\end{array}$ & 3.7 & N/A & VUS $^{*}$ \\
\hline CUL4B & c. $[830 \mathrm{~A}>\mathrm{G}]$ & p.[E277G] & Missense & $\begin{array}{c}\text { Not } \\
\text { detectable }\end{array}$ & 4.9 & 0.527 & Pathogenic \\
\hline MED12 & c. $[5746 \mathrm{C}>\mathrm{T}]$ & p.[Q1916*] & Nonsense & $\begin{array}{c}\text { Not } \\
\text { detectable }\end{array}$ & 6.25 & N/A & Pathogenic \\
\hline
\end{tabular}

Abbreviations: HGVS: Human Genome Variation Society; P2 cart: Patient 2 cartilaginous component; P2 noncart: Patient 2 noncartilaginous component; VUS: variants of unknown significance; N/A: Not available.

* SIFT $=0.25$, Polyphen- $2=0.557$ for HDAC6: c. $[2764 \mathrm{C}>\mathrm{T}]$

small molecule inhibitors for RTKs slow tumor cell growth. NTRK1 is a transmembrane protein receptor for nerve growth factor. After ligand binding, NTRK1 first autophosphorylates at five auto-phosphorylation residues (Y496, Y676, Y680, Y681, and Y791) and then phosphorylates downstream molecules, such as $\mathrm{p} 44 / 42[23,24]$. Activating mutations typically result from genomic rearrangements in papillary thyroid carcinoma and lung cancer [25], and missense mutations rarely lead to overactivation [23]. The NTRK1 c.[1925C $>$ T] resulted in a missense mutation of the NTRK1 protein p.[A642V] in the intracellular domain of the NTRK1 protein. We were able to visualize the spatial distances between the four auto-phosphorylated tyrosine residues and the amino acid change A642V (Figure 3B); the nearest distance of $23.80 \AA$ was between Y 680 and A642V. Thus, the NTRK1 p.[A642V] mutation should not directly interfere with the phosphorylation process, and the phospho-p44/42 status should be independent of the NTRK1 p.[A642V] mutation. Interestingly, phospho-p44/42 exhibited positivity in approximately $45 \%$ of the cells of P1-S1. The staining pattern was not homogenous for this marker in P1-S2 noncartilaginous component; some areas exhibited more tumor cells that were positive for this marker than did others. The average percentage of tumor cells positive for this marker was $14 \%$. Approximately $55 \%$ of the cells were positive in the P1-S2 cartilaginous component (Figure 3C). This result suggests that phospho-p44/42 might not be involved in the tumor progression. In addition, the $J A K 1$ c. $[383 \mathrm{G}>\mathrm{A}]$ mutation was previously identified in an endometrial carcinoma sample from the Cancer Genome Atlas (TCGA) project. Phospho-Stat3, a well-known target of the JAK1 protein, exhibited positivity in less than $5-8 \%$ of cells in the P1-S1, $3 \%$ of cells in the P1-S2 noncartilaginous component and $6 \%$ of cells in the P1-S2 cartilaginous component (Figure 3C). This result suggests that the JAKI mutation might not be an activating mutation in Patient 1.

We speculated that a TP53-mutated DDCS cancer cell might lose its surveillance over genomic instability after radiation, which might have induced a $P T E N$ deletion in Patient 1. The combined TP53 and PTEN changes further promoted tumor progression (Figure 3D).

\section{DISCUSSION}

In this paper, we reported two patients of DDCS with mutation analysis of selected genes.

The main focus of the current study was to gain insight into the pathogenesis of disease progression of DDCS. The mechanism that contributes to the disease progression from the cartilaginous component to the noncartilaginous sarcomatous component remains unclear. The present study proposed a mechanism for disease progression in which combined TP53 and PTEN changes promote tumor progression in DDCS. Indeed, PTEN gene mutations are rare in chondrosarcoma, and Lin et al reported that a PTEN mutation was detected in only one out of forty chondrosarcoma cases [26]. Alterations in the PTEN gene are frequently observed after radiation when TP53 is null or heterozygous in lymphoma [27]. TP53 mutation or loss has been implicated in other types of sarcoma [28-30]. The concurrent loss of function in PTEN and TP53 provided an explanation for rapid disease progression at the time of cancer recurrence for other tumors, which was also the case for invasive bladder cancer [31]. In addition, RTK has been reported to be activated in this type of tumor [22]. However, the NTRK1 mutation proves not to be an activating mutation in Patient 1. 
Both patients recurred after radiation therapy. Indeed, only a few cases of DDCS in the skull base have been reported, including two patients with a history of prior radiation therapy to the maxillary and frontal bone regions years before the onset of DDCS [9, 32]. The first issue is whether radiation 'induced' the occurrence of the dedifferentiated component in DDCS. Our study cannot answer this question with certainty. In general, conventional skull base chondrosarcomas respond well to surgery combined with radiation therapy [33, 34]. However, if the diagnosis is DDCS, then prognosis is poor Indeed, it is very challenging for a pathologist to make the diagnosis of DDCS when the cartilaginous component is absent or unavailable. Patient 1 exhibited nearly no morphological relevance to chondrosarcoma in the first surgery, possibly due to incomplete surgical resection, with only spindle-shaped tumor cells.

Previous studies have suggested that the noncartilaginous component might derive from the cartilaginous component with additional mutations. Ropke et al reported that LOHs of the TP53 and $R B$ genes were exclusively found in the noncartilaginous component [8]. Terek et al reported that likely-mutated TP53 protein was accumulated in the noncartilaginous but not cartilaginous components of DDCS [35]. Grote et al reported a TP53 mutation that occurred exclusively in the noncartilaginous

A
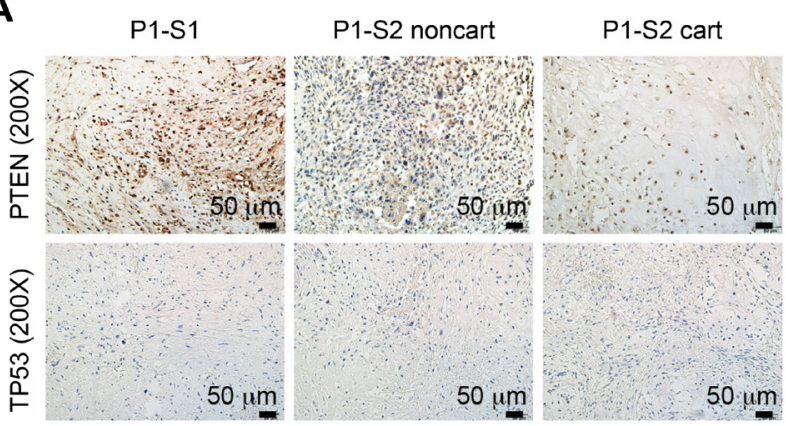

P2 noncart

P2 cart
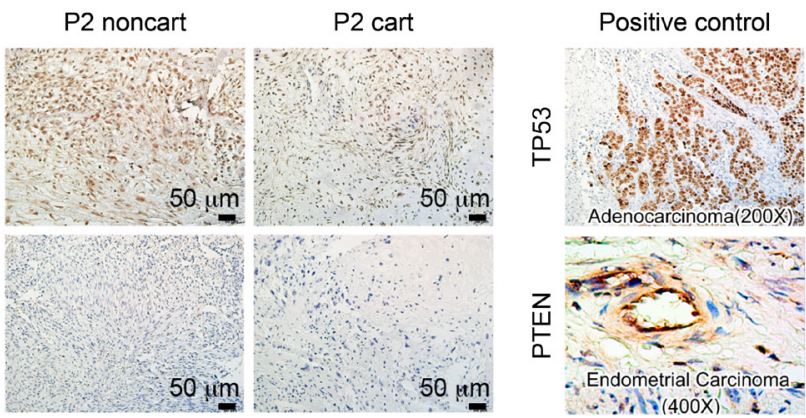

B

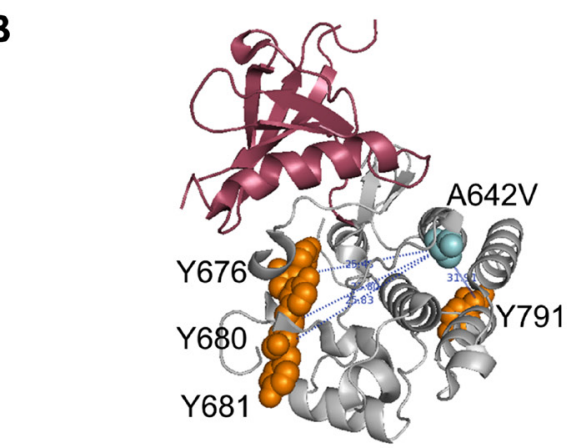

D

C

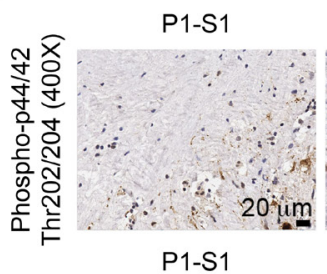

P1-S2 noncart
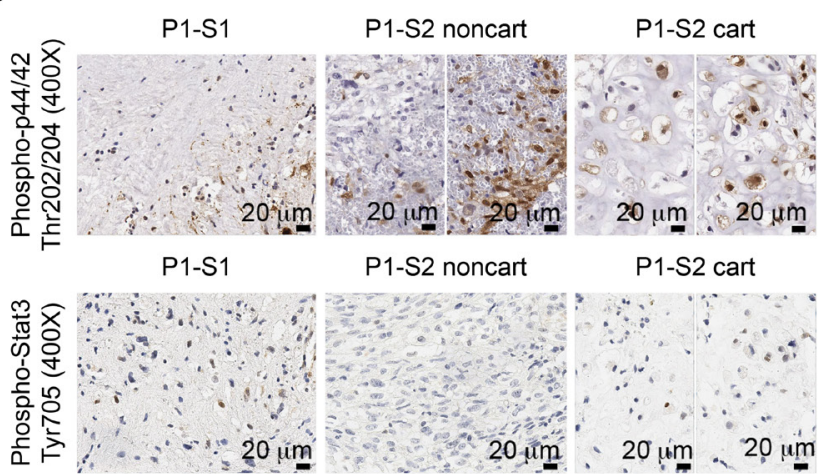

P1-S2 noncart

P1-S2 cart

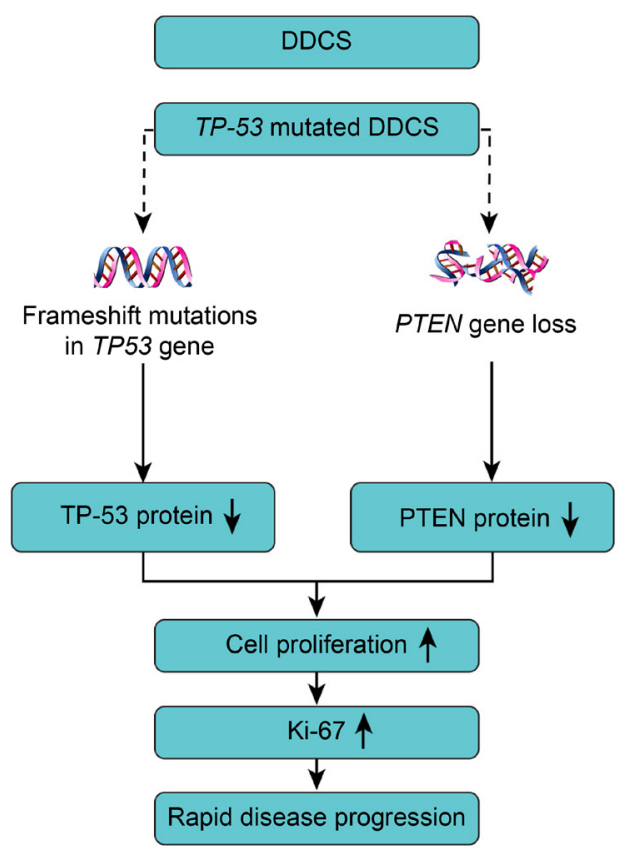

Figure 3: Combined TP53 and PTEN alterations accounted for disease progression. A. Immunostaining of PTEN and TP53 in surgical specimens from P1-S1, P1-S2 noncartilaginous component (P1-S2 noncart), P1-S2 cartilaginous component (P1-S2 cart), Patient 2 noncartilaginous component (P2 noncart) and Patient 2 cartilaginous component (P2 cart) (left panel). Positive controls for TP53 and PTEN were adenocarcinoma and endometrial tumors, respectively (right panel). B. Three-dimensional (3D) structural view of the NTRK1 protein. The distance from mutated the A642V to the Y676, Y680, Y681, and Y791 residues were 25.48 $\AA, 23.80 \AA, 25.83$ $\AA$, and $31.91 \AA$, respectively. C. Immunostaining of phospho-p44/42 (Thr202/204) and phospho-Stat3 (Tyr705). D. Proposed schematic illustration of the disease progression due to the combined TP53 and PTEN changes. 
component [11]. Simms et al demonstrated increased TP53 staining in the spindle-cell portion of eight DDCS cases, whereas all of the cartilaginous components showed weak or no staining [36]. In our study, the non-cartilaginous component of P1-S1 shared common mutations in TP53, $J A K 1, M A P K 8 I P 1$ and NTRK1 in the mixed sample of P1-S2. However, the P1-S2 sample exhibited additional mutations in other genes, including a PTEN deletion. The TP53 immunostaining was negative for both Patient 1 and Patient 2. Patient 1 had a frameshift mutation in the TP53 gene encoding pre-truncated TP53 proteins, which explains the negative TP53 immunostaining for this patient. For Patient 2, we speculate that the wild-type TP53 protein was low in abundance in comparison with the positive control and below the detection threshold of TP53 immunostaining in the current setting.

One major limitation of our study was that the number of sequenced genes was limited. The targeted NGS only included the predefined exonic regions of 508 genes. Therefore, epigenetic changes, genomic rearrangement, and genes outside of that panel could not be detected. Indeed, one study suggested that both genetic and epigenetic alterations might occur in DDCS [8].

In conclusion, the present study provided evidence that the rapid progression and increased Ki-67 index likely resulted from the concurrent mutations in TP53 and PTEN genes. The multiple gene alternations detected in the present study suggest that there might be other molecular pathways contributing the progression of DDCS as well.

\section{MATERIALS AND METHODS}

\section{Ethical approval}

The study protocol was reviewed and approved by the Ethnical Committee of Peking Union Medical College Hospital. The two patients provided signed informed consent to approve the portion of the surgical specimens for research purposes.

\section{${ }^{18}$ F-FDG and ${ }^{68}$ Ga DOTATATE PET/CT imaging}

One patient was IV-injected with $370 \mathrm{MBq}$ of ${ }^{18} \mathrm{~F}-\mathrm{FDG}$ and $120 \mathrm{MBq}$ of ${ }^{68} \mathrm{Ga}$ DOTATATE (a novel somatostatin analog), respectively. One hour later, the PET/CT images were acquired using a Siemens Biograph TruePoint True V PET/CT (Knoxville, TN, USA) combining 64-slice CT with a supine position.

\section{Targeted NGS and validation}

Tumor DNA was extracted from formalin-fixed paraffin-embedded (FFPE) samples and fresh frozen samples using the QIAamp DNA FFPE Tissue Kit and the DNEasy Blood and Tissue Extraction Kit (Qiagen, Hilden,
Germany), respectively, according to the manufacturer's instructions. All FFPE and fresh frozen tissue samples underwent $\mathrm{H} \& \mathrm{E}$ staining and were reviewed by a pathologist to ensure $>70 \%$ tumor content. DNA purity and concentration were assessed using a NanoDrop2000 spectrophotometer (Thermo Fisher Scientific, Florida, USA); DNA quality was assessed by agarose gel electrophoresis.

Library construction was performed as previously described using $1 \mu \mathrm{g}$ of DNA sheared by an ultrasonoscope to generate fragments with a peak length of $250 \mathrm{bps}$, followed by end repair, A tailing and ligation to the Illumina-indexed adapters according to the standard library construction protocol. Target enrichment was performed on a custom sequence captureprobe (Nimblegen, USA), which targeted 7,708 exons of 508 cancer-related genes and 78 introns from 19 genes recurrently rearranged in solid tumors, representing approximately $1.7 \mathrm{Mb}$ of the human genome in total (Supplementary Table 1). Sequencing was performed with $2 \times 101-b p$ paired-end reads and an 8-bp index read on an Illumina Hiseq 2500 platform (Illumina, San Diego, USA) using the manufacturer's protocols.

Primary sequence data were first processed by filtering adaptor sequences and removing low-quality reads using the SOAPnuke software developed by BGI and then aligned to build hg19 of the NCBI reference genome assembly using the BWA aligner v0.6.2-r126. Polymerase chain reaction (PCR) duplicate reads were removed by PICARD v1.98. Local realignment, base quality score recalibration was performed using GATK v2.3-9, and poorly mapped reads were removed based on the recalibration result. SNVs were detected by Standard BGI in-house NGS analysis SOMATK-SNV (developed by BGI, manuscript in preparation), and Indels (small insertions and deletions) were detected by SOMATKINDEL (developed by BGI, manuscript in preparation). Copy number variation (CNV) calling was performed by CONTRA v2.0.4. Known SNPs and Indels obtained from the 1000 Genomes project were discarded. The remaining variants were subdivided into four categories: (1) variants that were previously reported to be deleterious; (2) variants that were likely to be gene-disrupting, including nonsense and splicing mutations and frameshift caused by Indels; (3) missense mutations that were judged to be pathogenic by Condel software [37] and those could not be predicted by Condel will be predicted by both SIFT and PolyPhen-2 [38, 39] (SIFT score $<0.05$ AND Polyphen-2 score > 0.85); (4) the remaining variants that were considered as variants of unknown significance (VUS). The first three categories were defined as pathogenic. Sanger bidirectional sequencing confirmed the detected mutations of NTRK1, JAK1, MAPK8IP1 and TP53 in P1$\mathrm{S} 2$. For comparison, SNVs were also called by MuTect v1.1.4 [40], and Indels were called by Varscan v2.3.6 [41]. 


\section{Pathological evaluation and immunohistochemistry staining}

The FFPE specimens were serially sectioned to generate $4-\mu \mathrm{m}$ unstained slides for H\&E staining and immunohistochemical studies with the following markers: S-100 (Abcam, Cat \#: ab34686, 1:250), vimentin (Abcam, Cat \#: ab92547, 1:250), CD68 (Abcam, Cat \#: ab955, 1:200), PTEN (Cell Signaling Technology, Cat \#: 9559, 1:100), TP53 (Abcam, Cat \#: ab4060, 1:100), Ki-67 (Cell Signaling Technology, Cat \#: 9027 1:200), phospho-p44/42 (Thr202/Tyr204) (Cell Signaling, Cat \#: 9101, 1:50), and phospho-Stat3 (Tyr705) (Cell Signaling Technology, Cat \#: 9145, 1:400). The immunohistochemical staining was performed according to the standardized protocols [42, 43].

\section{FISH test for PTEN gene loss}

The PTEN loss was confirmed by FISH (Vysis LSI PTEN SpectrumOrange/CEP 10 SpectrumGreen Probes Abbott, 07j74-001) with organ probes covering a 368$\mathrm{kb}$ length of chromosome 10q23, including the regions encoding PTEN, and green probes covering CEP 10 of alpha satellite of 10p11.1-q11.1 DNA.

\section{Amino acid distance estimation from the protein 3D structure}

The 3D protein structure file was downloaded from the RCSB Protein Data Bank. The distance was measured between the $\mathrm{Ca}$ atoms of the relative residues using PyMOL software.

\section{ACKNOWLEDGMENTS}

None.

\section{CONFLICTS OF INTEREST}

The authors declare no conflicts of interest.

\section{GRANT SUPPORT}

None.

\section{Author contributions}

L.G., X.H. and B.X. designed the study and drafted the manuscript. L.G., X.H., Xiaopeng G., R.C., J.N. conducted immunostaining. D.C. reviewed the immunostaining results. Xiaohuan G., X.C., P.T. conducted sequencing and data interpretation. T.D. wrote the section describing the clinical significance of radiation on DDCS therapy. Xinqi G. conducted 3D protein structure analysis. Y.Y., R.W., and B.X. were the doctors for the two patients. B.X. supervised the whole study.

\section{REFERENCES}

1. Grimer RJ, Gosheger G, Taminiau A, Biau D, Matejovsky Z, Kollender Y, San-Julian M, Gherlinzoni F, Ferrari C. Dedifferentiated chondrosarcoma: prognostic factors and outcome from a European group. Eur J Cancer. 2007; 43: 2060-2065.

2. Kahn LB. Chondrosarcoma with dedifferentiated foci. A comparative and ultrastructural study. Cancer. 1976; 37: 1365-1375.

3. Aigner $\mathrm{T}$, Dertinger $\mathrm{S}$, Neureiter $\mathrm{D}$, Kirchner $\mathrm{T}$. De-differentiated chondrosarcoma is not a 'de-differentiated' chondrosarcoma. Histopathology. 1998; 33: 11-19.

4. Aigner T, Unni KK. Is dedifferentiated chondrosarcoma a 'de-differentiated' chondrosarcoma? J Pathol. 1999; 189: 445-447.

5. Tetu B, Ordonez NG, Ayala AG, Mackay B. Chondrosarcoma with additional mesenchymal component (dedifferentiated chondrosarcoma). II. An immunohistochemical and electron microscopic study. Cancer. 1986; 58: 287-298.

6. Bovee JV, Cleton-Jansen AM, Rosenberg C, Taminiau AH, Cornelisse CJ, Hogendoorn PC. Molecular genetic characterization of both components of a dedifferentiated chondrosarcoma, with implications for its histogenesis. J Pathol. 1999; 189: 454-462.

7. Dickey ID, Rose PS, Fuchs B, Wold LE, Okuno SH, Sim FH, Scully SP. Dedifferentiated chondrosarcoma: the role of chemotherapy with updated outcomes. J Bone Joint Surg Am. 2004; 86-a: 2412-2418.

8. Ropke M, Boltze C, Neumann HW, Roessner A, SchneiderStock R. Genetic and epigenetic alterations in tumor progression in a dedifferentiated chondrosarcoma. Pathol Res Pract. 2003; 199: 437-444.

9. Amary MF, Bacsi K, Maggiani F, Damato S, Halai D, Berisha F, Pollock R, O'Donnell P, Grigoriadis A, Diss T, Eskandarpour M, Presneau N, Hogendoorn PC, et al. IDH1 and IDH2 mutations are frequent events in central chondrosarcoma and central and periosteal chondromas but not in other mesenchymal tumours. J Pathol. 2011; 224: 334-343.

10. Coughlan B, Feliz A, Ishida T, Czerniak B, Dorfman HD. p53 expression and DNA ploidy of cartilage lesions. Hum Pathol. 1995; 26: 620-624.

11. Grote HJ, Schneider-Stock R, Neumann W, Roessner A. Mutation of p53 with loss of heterozygosity in the osteosarcomatous component of a dedifferentiated chondrosarcoma. Virchows Arch. 2000; 436: 494-497.

12. Tyburczy ME, Jozwiak S, Malinowska IA, Chekaluk Y, Pugh TJ, Wu CL, Nussbaum RL, Seepo S, Dzik T, Kotulska K, Kwiatkowski DJ. A shower of second hit events as the cause of multifocal renal cell carcinoma in tuberous sclerosis complex. Hum Mol Genet. 2014; 24: 1836-1842. 
13. Boland GM, Piha-Paul SA, Subbiah V, Routbort M, Herbrich SM, Baggerly K, Patel KP, Brusco L, Horombe C, Naing A, Fu S, Hong DS, Janku F, et al. Clinical next generation sequencing to identify actionable aberrations in a phase I program. Oncotarget. 2015; 6: 20099-20110. doi: 10.18632/oncotarget.4040.

14. Movva S, Wen W, Chen W, Millis SZ, Gatalica Z, Reddy S, von Mehren M, Van Tine BA. Multi-platform profiling of over 2000 sarcomas: identification of biomarkers and novel therapeutic targets. Oncotarget. 2015; 6: 12234-12247. doi: 10.18632/oncotarget.3498.

15. Wei X, Dai Y, Yu P, Qu N, Lan Z, Hong X, Sun Y, Yang G, Xie S, Shi Q, Zhou H, Zhu Q, Chu Y, et al. Targeted next-generation sequencing as a comprehensive test for patients with and female carriers of DMD/BMD: a multipopulation diagnostic study. Eur J Hum Genet. 2014; 22: 110-118.

16. Kerr DA, Lopez HU, Deshpande V, Hornicek FJ, Duan Z, Zhang Y, Rosenberg AE, Borger DR, Nielsen GP. Molecular distinction of chondrosarcoma from chondroblastic osteosarcoma through IDH1/2 mutations. Am J Surg Pathol. 2013; 37: 787-795.

17. Petitjean A, Mathe E, Kato S, Ishioka C, Tavtigian SV, Hainaut P, Olivier M. Impact of mutant p53 functional properties on TP53 mutation patterns and tumor phenotype: lessons from recent developments in the IARC TP53 database. Hum Mutat. 2007; 28: 622-629.

18. Cerami E, Gao J, Dogrusoz U, Gross BE, Sumer SO, Aksoy BA, Jacobsen A, Byrne CJ, Heuer ML, Larsson E, Antipin Y, Reva B, Goldberg AP, et al. The cBio cancer genomics portal: an open platform for exploring multidimensional cancer genomics data. Cancer Discov. 2012; 2: 401-404.

19. Gao J, Aksoy BA, Dogrusoz U, Dresdner G, Gross B, Sumer SO, Sun Y, Jacobsen A, Sinha R, Larsson E, Cerami E, Sander C, Schultz N. Integrative analysis of complex cancer genomics and clinical profiles using the cBioPortal. Sci Signal. 2013; 6: pl1.

20. Barretina J, Taylor BS, Banerji S, Ramos AH, LagosQuintana M, Decarolis PL, Shah K, Socci ND, Weir BA, Ho A, Chiang DY, Reva B, Mermel CH, et al. Subtypespecific genomic alterations define new targets for softtissue sarcoma therapy. Nat Genet. 2010; 42: 715-721.

21. Stern H, Gardner H, Burzykowski T, Elatre W, O'Brien C, Lackner MR, Pestano GA, Santiago A, Villalobos I, Eiermann W, Pienkowski T, Martin M, Robert NJ, et al. PTEN loss is associated with worse outcome in HER2amplified breast cancer patients but is not associated with trastuzumab resistance. Clin Cancer Res. 2015; 21: 2065-2074.

22. Shen CH, Yuan P, Perez-Lorenzo R, Zhang Y, Lee SX, Ou Y, Asara JM, Cantley LC, Zheng B. Phosphorylation of BRAF by AMPK impairs BRAF-KSR1 association and cell proliferation. Mol Cell. 2013; 52: 161-172.

23. Pierotti MA, Greco A. Oncogenic rearrangements of the NTRK1/NGF receptor. Cancer Lett. 2006; 232: 90-98.
24. Vaishnavi A, Capelletti M, Le AT, Kako S, Butaney M, Ercan D, Mahale S, Davies KD, Aisner DL, Pilling AB, Berge EM, Kim J, Sasaki H, et al. Oncogenic and drugsensitive NTRK1 rearrangements in lung cancer. Nat Med. 2013; 19: 1469-1472.

25. Pierotti MA, Bongarzone I, Borello MG, Greco A, Pilotti S, Sozzi G. Cytogenetics and molecular genetics of carcinomas arising from thyroid epithelial follicular cells. Genes Chromosomes Cancer. 1996; 16: 1-14.

26. Lin C, Meitner PA, Terek RM. PTEN mutation is rare in chondrosarcoma. Diagn Mol Pathol. 2002; 11: 22-26.

27. Mao JH, Wu D, Perez-Losada J, Nagase H, DelRosario $\mathrm{R}$, Balmain A. Genetic interactions between Pten and p53 in radiation-induced lymphoma development. Oncogene. 2003; 22: 8379-8385.

28. McKinnon T, Venier R, Dickson BC, Kabaroff L, Alkema M, Chen L, Shern JF, Yohe ME, Khan J, Gladdy RA. Kras activation in p53-deficient myoblasts results in high-grade sarcoma formation with impaired myogenic differentiation. Oncotarget. 2015; 6: 14220-14232. doi: 10.18632/oncotarget.3856.

29. Ribi S, Baumhoer D, Lee K, Edison, Teo AS, Madan B, Zhang K, Kohlmann WK, Yao F, Lee WH, Hoi Q, Cai $\mathrm{S}$, Woo XY, et al. TP53 intron 1 hotspot rearrangements are specific to sporadic osteosarcoma and can cause Li-Fraumeni syndrome. Oncotarget. 2015; 6: 7727-7740. doi: 10.18632/oncotarget.3115.

30. Landuzzi L, Ianzano ML, Nicoletti G, Palladini A, Grosso V, Ranieri D, Dall'Ora M, Raschi E, Laranga R, Gambarotti M, Picci P, De Giovanni C, Nanni P, et al. Genetic prevention of lymphoma in p53 knockout mice allows the early development of p53-related sarcomas. Oncotarget. 2014; 5: 11924-11938. doi: 10.18632/oncotarget.2650.

31. Puzio-Kuter AM, Castillo-Martin M, Kinkade CW, Wang X, Shen TH, Matos T, Shen MM, Cordon-Cardo C, AbateShen C. Inactivation of p53 and Pten promotes invasive bladder cancer. Genes Dev. 2009; 23: 675-680.

32. Davies BW, Prescott CR, Said SA, Campana J, Attie-Castro FA, Velasco ECAA, Durairaj VD. Radiation-induced dedifferentiated chondrosarcoma with orbital invasion. Ophthal Plast Reconstr Surg. 2014; 30: 205-208.

33. Noel G, Habrand JL, Jauffret E, de Crevoisier R, Dederke S, Mammar H, Haie-Meder C, Pontvert D, Hasboun D, Ferrand R, Boisserie G, Beaudre A, Gaboriaud G, et al. Radiation therapy for chordoma and chondrosarcoma of the skull base and the cervical spine. Prognostic factors and patterns of failure. Strahlenther Onkol. 2003; 179: 241-248.

34. Rosenberg AE, Nielsen GP, Keel SB, Renard LG, Fitzek MM, Munzenrider JE, Liebsch NJ. Chondrosarcoma of the base of the skull: a clinicopathologic study of 200 cases with emphasis on its distinction from chordoma. Am J Surg Pathol. 1999; 23: 1370-1378.

35. Terek RM, Healey JH, Garin-Chesa P, Mak S, Huvos A, Albino AP. p53 mutations in chondrosarcoma. Diagn Mol Pathol. 1998; 7: 51-56. 
36. Simms WW, Ordonez NG, Johnston D, Ayala AG, Czerniak B. p53 expression in dedifferentiated chondrosarcoma. Cancer. 1995; 76: 223-227.

37. Gonzalez-Perez A, Lopez-Bigas N. Improving the assessment of the outcome of nonsynonymous SNVs with a consensus deleteriousness score, Condel. Am J Hum Genet. 2011; 88:440-449.

38. Adzhubei IA, Schmidt S, Peshkin L, Ramensky VE, Gerasimova A, Bork P, Kondrashov AS, Sunyaev SR. A method and server for predicting damaging missense mutations. Nat Methods. 2010; 7:248-249.

39. Ng PC, Henikoff S. Predicting deleterious amino acid substitutions. Genome Res. 2001; 11:863-874.

40. Cibulskis K, Lawrence MS, Carter SL, Sivachenko A, Jaffe D, Sougnez C, Gabriel S, Meyerson M, Lander ES, Getz G. Sensitive detection of somatic point mutations in impure and heterogeneous cancer samples. Nat Biotechnol. 2013; 31: 213-219.
41. Koboldt DC, Zhang Q, Larson DE, Shen D, McLellan MD, Lin L, Miller CA, Mardis ER, Ding L, Wilson RK. Varscan 2: Somatic mutation and copy number alteration discovery in cancer by exome sequencing. Genome Res. 2012; 22: 568-576.

42. Hong X, Zhang J, Wu Q, Wang W, Ye AY, Song W, Dai $\mathrm{H}$, Wang X, Wu F, You L, Wu W, Zhao Y. Challenges in detecting pre-malignant pancreatic lesions during acute pancreatitis using a serum microRNA assay: a study based on KrasG12D transgenic mice. Oncotarget Mar 17. 2016; doi: 10.18632/oncotarget.8148.

43. Wu W, Hong X, Li J, Dai M, Wang W, Tong A, Zhu Z, Dai H, Zhao Y. Solid serous cystadenoma of the pancreas: a case report of 2 patients revealing vimentin, beta-catenin, alpha-1 antitrypsin, and alpha-1 antichymotrypsin as new immunohistochemistry staining markers. Medicine (Baltimore). 2015; 94: e644. 